\title{
BioEarth: Envisioning and developing a new regional earth system model to inform natural and agricultural resource management
}

\author{
Jennifer C. Adam • Jennie C. Stephens • \\ Serena H. Chung • Michael P. Brady • R. David Evans • \\ Chad E. Kruger • Brian K. Lamb • Mingliang Liu • \\ Claudio O. Stöckle • Joseph K. Vaughan • \\ Kirti Rajagopalan • John A. Harrison • \\ Christina L. Tague • Ananth Kalyanaraman • \\ Yong Chen • Alex Guenther • Fok-Yan Leung • \\ L. Ruby Leung • Andrew B. Perleberg • \\ Jonathan Yoder • Elizabeth Allen • Sarah Anderson • \\ Bhagyam Chandrasekharan • Keyvan Malek • \\ Tristan Mullis • Cody Miller • Tsengel Nergui • \\ Justin Poinsatte • Julian Reyes • Jun Zhu • \\ Janet S. Choate $\cdot$ Xiaoyan Jiang • Roger Nelson • \\ Jin-Ho Yoon • Georgine G. Yorgey • Kristen Johnson • \\ Kiran J. Chinnayakanahalli • Alan F. Hamlet • \\ Bart Nijssen • Von Walden
}

Received: 4 April 2013 / Accepted: 15 March 2014 / Published online: 24 April 2014

(C) The Author(s) 2014. This article is published with open access at Springerlink.com

\begin{abstract}
As managers of agricultural and natural resources are confronted with uncertainties in global change impacts, the complexities associated with the interconnected cycling of nitrogen, carbon, and water present daunting management challenges. Existing models provide detailed information on specific sub-systems (e.g., land, air, water, and economics). An increasing awareness of the unintended consequences of management decisions resulting from interconnectedness of these sub-systems, however, necessitates coupled regional earth system models (EaSMs). Decision makers' needs and priorities can be integrated into the model design and development processes to enhance decision-making relevance and "usability" of EaSMs. BioEarth is a research initiative currently under development with a focus on the U.S.
\end{abstract}

This article is part of a Special Issue on "Regional Earth System Modeling" edited by Zong-Liang Yang and Congbin Fu.

J. C. Adam $(\bowtie) \cdot$ S. H. Chung $\cdot$ M. P. Brady • R. D. Evans • B. K. Lamb • M. Liu • C. O. Stöckle •

J. K. Vaughan $\cdot$ K. Rajagopalan $\cdot$ A. Kalyanaraman $\cdot$ A. Guenther $\cdot$ F.-Y. Leung $\cdot$ J. Yoder $\cdot$ E. Allen $\cdot$

S. Anderson • B. Chandrasekharan $\cdot$ K. Malek $\cdot$ T. Mullis $\cdot$ T. Nergui $\cdot$ J. Poinsatte $\cdot$ J. Reyes $\cdot$ R. Nelson $•$

K. Johnson $\cdot$ V. Walden

Washington State University, Pullman, WA, USA

e-mail: jcadam@wsu.edu 
Pacific Northwest region that explores the coupling of multiple stand-alone EaSMs to generate usable information for resource decision-making. Direct engagement between model developers and non-academic stakeholders involved in resource and environmental management decisions throughout the model development process is a critical component of this effort. BioEarth utilizes a bottom-up approach for its land surface model that preserves fine spatialscale sensitivities and lateral hydrologic connectivity, which makes it unique among many regional EaSMs. This paper describes the BioEarth initiative and highlights opportunities and challenges associated with coupling multiple stand-alone models to generate usable information for agricultural and natural resource decision-making.

\section{Introduction}

The underutilization of climate science information for decision making is increasingly being acknowledged (Weaver et al. 2013). Different types of research projects are emerging that are designed to close the gap between climate science information that is deemed useable by scientists versus that by non-academic societal actors (Lemos et al. 2012). Societal actors involved in agricultural and natural resource decision-making are confronted with uncertainties in global change impacts and the interconnected challenges of managing nitrogen $(\mathrm{N})$, carbon (C), and water $\left(\mathrm{H}_{2} \mathrm{O}\right)$. However, most climate change impact work relies on models that only simulate specific sub-systems (e.g., land, air, or water). The interconnectedness of these systems is often poorly understood and difficult to conceptualize; thus resource management decisions made with the best intentions can lead to unintended consequences. To better understand

J. C. Stephens

Clark University, Worcester, MA, USA

C. E. Kruger • A. B. Perleberg

Washington State University, Wenatchee, WA, USA

J. A. Harrison • C. Miller

Washington State University, Vancouver, WA, USA

C. L. Tague $\cdot$ J. Zhu $\cdot$ J. S. Choate

University of California, Santa Barbara, CA, USA

Y. Chen

Oregon State University, Corvallis, OR, USA

A. Guenther $\cdot$ L. R. Leung $\cdot$ J.-H. Yoon

Pacific Northwest National Laboratory, Richland, WA, USA

$\mathrm{X}$. Jiang

National Center for Atmospheric Research, Boulder, CO, USA

G. G. Yorgey

Washington State University, Seattle, WA, USA

K. J. Chinnayakanahalli

AIR Worldwide, Boston, MA, USA

A. F. Hamlet

Notre Dame University, Notre Dame, IN, USA

B. Nijssen

University of Washington, Seattle, WA, USA 
interconnections among sub-systems, coupled earth system models (EaSMs) are essential. To enhance decision-making relevance and usability of existing and developing EaSMs, these models need to be capable of quantifying the impacts of specific management practices such that model outputs can be communicated in a manner that is relevant to decision-makers.

EaSMs have evolved in recent years by incorporation of biogeochemical processes and vegetation dynamics in climate models (Washington et al. 2009). Currently, many EaSMs are being further developed to resolve coupled human and natural systems (CHANS), including representation of resource management activities. Examples include the Community Earth System Model (CESM; www2.cesm.ucar.edu) and the Platform for Regional Integrated Modeling and Analysis (PRIMA; Kraucunas et al. 2013). CAM-chem, the Community Atmosphere Model (CAM) in CESM, has been developed to study the interactions between climate and atmospheric chemistry, thus allowing for the analysis of the impact of climate change on air quality (Lamarque et al. 2012). The Community Land Model (CLM) (Lawrence et al. 2011), the land surface model for CESM, has recently been developed to represent some agricultural and water management activities (e.g., Drewniak et al. 2013). Including economic decision making in EaSMs is starting to emerge; computable partial and general equilibrium models (CGE) and, increasingly, agent-based models (ABM) have been connected to biophysical models (Harou et al. 2009; Rowan et al. 2011) allowing for better representation of CHANS when captured in an EaSM framework.

Although tremendous progress is being made towards resolving resource management activities in integrated models, funding and decision-making agencies (e.g., the U.S. Department of Agriculture) as well as scientists (e.g., Reid et al. 2010) are calling for additional advancements to quantify impacts on and feedbacks from ecological, agricultural, and other human systems; and effectively communicate model results for informing decisions. Resolving EaSMs at finer spatial and temporal scales is instrumental to making these advancements (Liu et al. 2007). Regional EaSMs have greater potential than those at global scales to improve both the technical understanding of complex interconnected environmental processes (including the role that humans play in these processes) and the relevance of information for decision-making (Giorgi 1995; Hibbard and Janetos 2013). For relevance to land-use decision-making, annual to decadal time-scales are critical (Smith et al. 2011). Annual variability is important to capture because certain management decisions (e.g., planting decisions) are made at this scale, and managers must cope with changes in variability as well as changes in means (Katz and Brown 1992). Other decisions are made at decadal scales; farm-level irrigation infrastructure and machinery generally have investment payback periods of about a decade, and perennial crops have an investment term of 3-30 years. Many U.S. state planning agencies operate on a 20 -year time horizon.

BioEarth is a research initiative currently under development that is designed to explore the coupling of multiple stand-alone models within a modular EaSM framework to generate usable information for agricultural and natural resource decision-making at the regional scale. This framework integrates atmospheric, terrestrial, aquatic, and economic models. BioEarth utilizes a bottom-up approach for its land surface model that preserves relatively fine spatial-scale sensitivities and lateral hydrologic connectivity, which makes it unique among many regional EaSMs. Our economics modeling utilizes a two-pronged approach that allows for both rich economic analysis through CGE and a more integrated biophysical-economic approach through the spatially-explicit $\mathrm{ABM}$, which also allows for consideration of non-economic information such as social norms. Modeled decisions are sensitive to variability at multiple time-scales and are informed by feedback provided by non-academic stakeholders. This project can benefit the broader scientific community by supporting and informing other regional modeling efforts that seek to integrate sub-systems with complex interconnections and produce useable climate science information to decision-makers. The purpose of this paper is to provide a high-level overview of BioEarth; the results for focused questions (pertaining to specific aspects of BioEarth) are forthcoming in other research articles. 


\section{Overview of BioEarth}

\subsection{Project goal}

The overarching goal of BioEarth is to improve understanding of the interactions between coupled $\mathrm{C}: \mathrm{N}: \mathrm{H}_{2} \mathrm{O}$ dynamics and human actions at regional and decadal scales under global change to 1) better understand the role that resource management actions have in impacting earth system dynamics, and 2) inform resource managers about the consequences of their

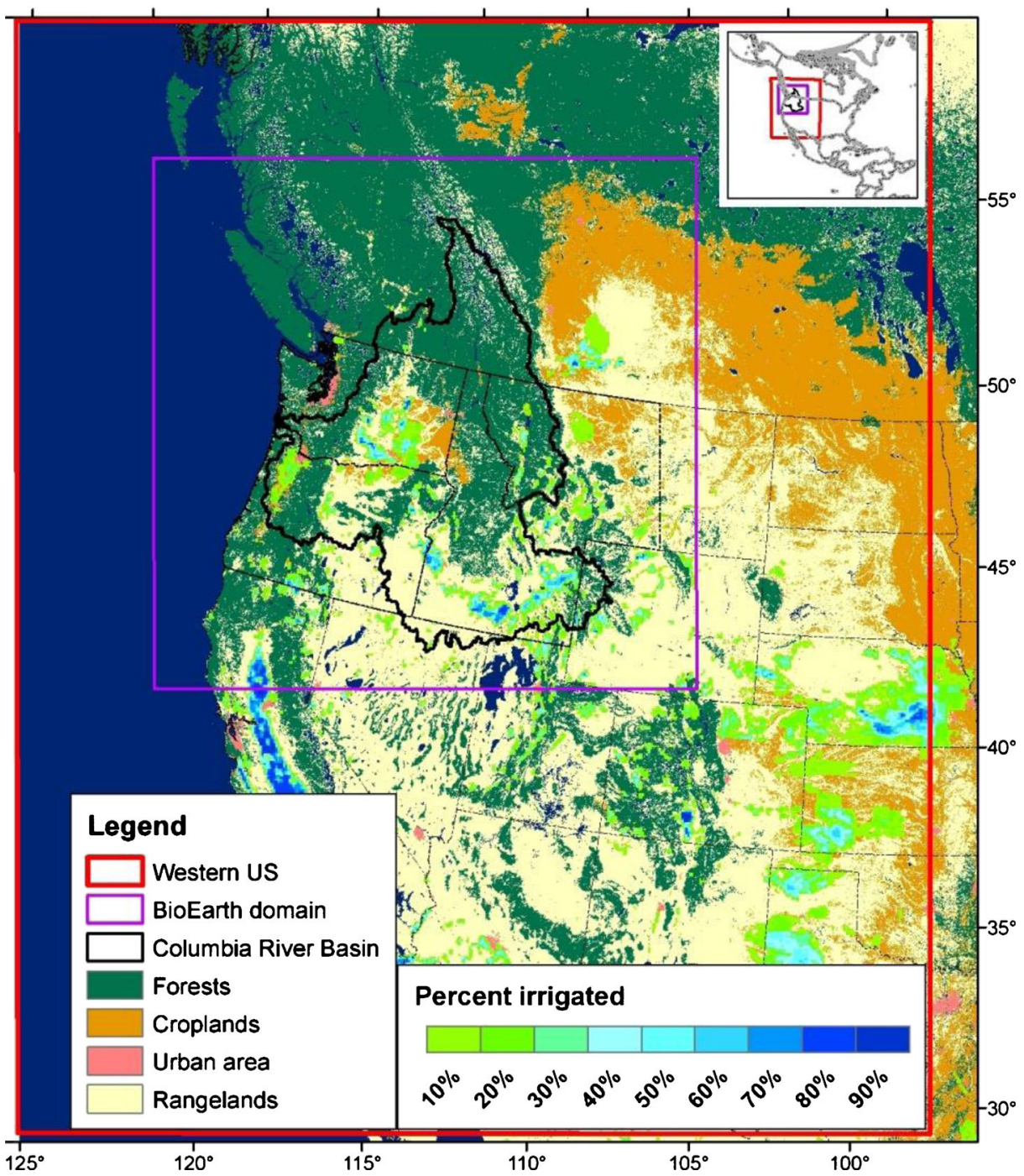

Fig. 1 Map of the BioEarth domain within the PNW region (purple rectangle) nested within the larger western U.S. domain (red rectangle) for physical atmospheric (WRF model) and land surface processes only. The economic and aquatic model components (streamflow routing, reservoirs, and nutrient export) are implemented only within the CRB (black outline). The land cover data are a combination of sources, including the 2011 USDA Cropland Data Layer and irrigation data from Ozdogan and Gutman (2008) 
decisions on the earth system, with a particular focus on quantifying uncertainties, environmental feedbacks, and economic and environmental tradeoffs. BioEarth enables users to quantify the impacts of human decisions on greenhouse gases and other atmospheric pollutants, water quantity and quality, terrestrial ecosystem health, and economics through simulating the management of cropping systems (e.g., crop selection, irrigation, fertilization, and residue management), forested ecosystems (e.g., thinning and restoration), rangeland ecosystems (e.g., grazing and restoration), water supply management (e.g., reservoirs, water rights curtailment, and water transfers), and air quality (e.g., regulation of emissions of pollutant and pollutant precursors from cars, power plants, and industrial facilities). This information, when combined with other more issue-specific decision-support tools and the constraints (e.g., economic, regulatory, or physical) and priorities of a decision-maker, allows for improved decision-making.

\subsection{Study domain}

The BioEarth project focuses on the PNW region of the U.S. (Fig. 1). As the fourth largest river in North America (as measured by flow), the Columbia River Basin (CRB) drains complex topography within the Cascade and Rocky Mountain Ranges and from the Snake River Plain. The region has extensive and diverse agricultural lands interspersed with heavily populated urban areas and surrounded by largely untransformed ecosystems; these lands provide a vast array of agricultural and natural resources. Much of the diversity in resources is due to the large gradient in climate across the basin. Winter-dominated precipitation and cold winters result in large seasonal storage of water in the snowpack, providing a natural reservoir that supports summer water needs but that is vulnerable to warming (Mote et al. 2003). Storm patterns are closely tied to the jet stream position and sensitive to long-term circulation patterns, including the El Niño Southern Oscillation and the Pacific Decadal Oscillation. These climate patterns affect temperature (Mote et al. 2003), precipitation (Wang et al. 2009), ecosystem exchange (Wharton et al. 2009), and forest fire regimes (Kitzberger et al. 2007). The PNW is also influenced by long-range import of air pollutants from Asia (Jaffe et al. 1999). Global change is expected to impact ecosystems through warming, perturbations to precipitation patterns, changes in extreme meteorological events, and increased transport from Asian sources. Concurrent steady increases in human population are applying pressures on natural resources with continued demand for environmental services. The sum of these effects presents a complex array of uncertainties to public decision-makers struggling to address all of these issues. The diversity of resources and complexity of issues in this region make it an ideal test-bed for the BioEarth framework for eventual application over other regions of the world.

\section{The BioEarth modeling framework}

\subsection{Overview of framework}

The BioEarth framework is developed via integration of existing model components; by choosing among the most sophisticated models, the integrated modeling framework will continually improve as each component develops. Each of the stand-alone models within the framework is an open-source community model in continuous development, allowing the BioEarth framework to benefit from the model development efforts of the larger scientific community. This framework encompasses atmospheric, terrestrial, aquatic, and economic 


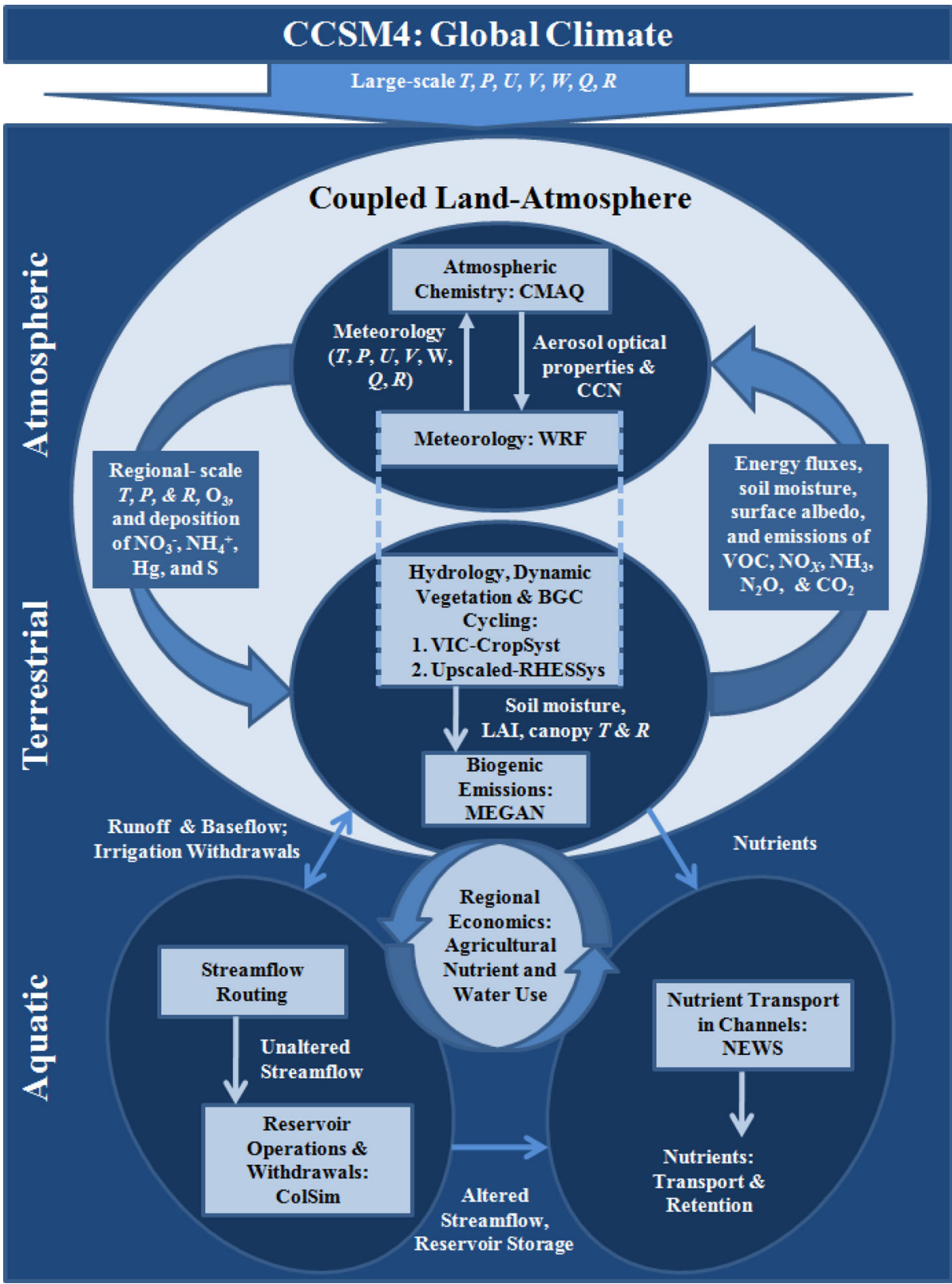

Fig. 2 Linkages between the atmospheric, terrestrial, aquatic, and economic components that comprise the modular BioEarth framework. Descriptions of each of the stand-alone models are given in Table 1. Detailed here are some of the variables that are passed between stand-alone models: $T$ temperature, $P$ precipitation, $U, V, W$ wind speed components, $Q$ water mixing ratio, $\mathrm{R}$ radiation, $\mathrm{CCN}$ cloud condensation nuclei, $\mathrm{O}_{3}$ ozone, $\mathrm{NO}_{3}$ - nitrate, $\mathrm{NH}_{4+}$ ammonium, $\mathrm{Hg}$ mercury, $\mathrm{S}$ sulfur, $\mathrm{VOC}$ volatile organic compounds, $\mathrm{NO}_{\mathrm{x}} \mathrm{NO}+\mathrm{NO}_{2}$ nitric oxide + nitrogen dioxide, $\mathrm{NH}_{3}$ ammonia, $\mathrm{N}_{2} \mathrm{O}$ nitrous oxide, $\mathrm{CO}_{2}$ carbon dioxide, $\mathrm{LAI}$ leaf area index 
Table 1 Descriptions for each of the stand-alone models shown in Fig. 2

\begin{tabular}{|c|c|c|}
\hline Earth system component & Stand alone model & Key references \\
\hline Global climate: CCSM4 & $\begin{array}{l}\text { Community Climate System Model-4; Future WRF } \\
\text { simulations are driven by archived CCSM4 output } \\
\text { for the Intergovernmental Panel on Climate } \\
\text { Change's Fifth Assessment Report. }\end{array}$ & (Gent et al. 2011) \\
\hline Atmospheric chemistry: CMAQ & $\begin{array}{l}\text { The Community Multiscale Air Quality; CMAQ is a } \\
\text { photochemical transport model that is used to } \\
\text { simulate air quality and atmospheric deposition. } \\
\text { The model accounts for chemical interactions for } \\
\text { compounds in gas, aqueous, and aerosol phases } \\
\text { and is driven by meteorology, which governs } \\
\text { transport, deposition, and chemical reactions in the } \\
\text { atmosphere. CMAQ is implemented over the } \\
\text { PNW domain in Fig. } 1 \text {. }\end{array}$ & $\begin{array}{l}\text { (Byun and Schere } \\
\text { 2006) }\end{array}$ \\
\hline Meteorology: WRF & $\begin{array}{l}\text { Weather Research and Forecasting; WRF is a } \\
\text { mesoscale meteorological model that solves the } \\
\text { Navier-Stokes equation for atmospheric dynamics } \\
\text { and includes physics parameterizations to } \\
\text { represent short- and long-wave radiation, planetary } \\
\text { boundary layer, sub-grid eddy diffusion, convec- } \\
\text { tion, cloud microphysics, and land surface pro- } \\
\text { cesses. WRF is implemented over the western U.S. } \\
\text { domain (Fig. 1) at a spatial resolution of } 12 \mathrm{~km} \text {. }\end{array}$ & $\begin{array}{l}\text { (Skamarock et al. } \\
\text { 2008) }\end{array}$ \\
\hline $\begin{array}{l}\text { Macro-Scale land surface } \\
\text { hydrology: VIC }\end{array}$ & $\begin{array}{l}\text { Variable Infiltration Capacity; VIC was developed for } \\
\text { large-scale land-atmosphere interaction water } \\
\text { quantity applications }\left(1 / 16 \text { th }-2^{\circ}\right) \text {, in which sub- } \\
\text { grid variability is based on statistical relationships. } \\
\text { VIC accounts for key moisture and energy fluxes } \\
\text { between the land surface and the atmosphere. VIC } \\
\text { is implemented over the western U.S. domain } \\
\text { (Fig. 1) at a spatial resolution of } 12 \mathrm{~km} \text {. }\end{array}$ & (Liang et al. 1994) \\
\hline
\end{tabular}

Cropland biogeochemistry and dynamic vegetation: CropSyst

Forest and grassland ecohydrology and dynamic vegetation: RHESSys

Biogenic emissions: MEGAN

Water management: ColSim
Cropping Systems; CropSyst is a multi-crop model that simulates soil water budgets, nutrient budgets, $\mathrm{C}$ cycling, crop growth and yield, residue production, and other parameters under user-defined management options (including rotations, tillage, fertilization, and irrigation scheduling).

Regional Hydro-Ecologic Simulation System; RHESSys is a mechanistic catchment-scale model designed to simulate climate and land-use change impacts on ecosystem $\mathrm{C}$ and nutrient cycling and hydrology. RHESSys links well-established models of vegetation growth, nutrient uptake, and soil biogeochemistry with a fully-distributed hydrologic model that includes lateral surface and subsurface hydrologic connectivity. RHESSys also simulates resource competition between plant species, and plant mortality.

Model of Emissions of Gases and Aerosols from Nature; MEGAN is driven by land cover and environmental conditions supplied by WRF and the land surface models, and provides biogenic emissions as inputs to CMAQ.

Columbia River Simulation Model; ColSim considers the physical characteristics of the CRB water

(Stöckle et al. 2003)

(Tague and Band 2004)

(Guenther et al. 2012) 
Table 1 (continued)

\begin{tabular}{|c|c|c|}
\hline Earth system component & Stand alone model & Key references \\
\hline & $\begin{array}{l}\text { management system (reservoirs, run-of-river dams, } \\
\text { diversions, and return flows) and its reservoir op- } \\
\text { erating policies to generate reservoir rule curves as } \\
\text { a function of operating policy. ColSim is adapted } \\
\text { for BioEarth to include irrigation withdrawals and } \\
\text { a water rights curtailment process. }\end{array}$ & $\begin{array}{l}\text { (Hamlet and } \\
\text { Lettenmaier } \\
\text { 1999) }\end{array}$ \\
\hline Nutrient export in rivers: NEWS & $\begin{array}{l}\text { Nutrient Export from Water(S)heds; In BioEarth, } \\
\text { NEWS takes as input simulated hydrologic and } \\
\text { nutrient fluxes, and is utilized to predict annual } \\
\text { average nutrient fluxes, sources, and sinks for } \\
\text { various forms of nutrients and C at the sub-basin } \\
\text { scale. }\end{array}$ & $\begin{array}{l}\text { (Seitzinger et al. } \\
\text { 2005) }\end{array}$ \\
\hline
\end{tabular}

model components with varying levels of integration (Fig. 2). Regional economic analysis is linked to the terrestrial and aquatic components; the circular arrows in Fig. 2 represent CHANS feedbacks. Exogenous to the BioEarth framework are water regulatory institutions and other environmental policies. Description (and acronym expansion) for each of these stand-alone models is provided in Table 1; economic models are described in Section 3.6.

\subsection{Overview of coupling and integration strategy}

Varying levels of integration from one-way (a.k.a., "offline") to two-way (a.k.a., "online" or "full") coupling exist in this framework. The atmospheric and terrestrial models can either be linked offline or fully-coupled at 30- to 60-min time-steps. Many of the other components are coupled at longer time-steps (e.g., water rights curtailment decisions occur weekly). The Kepler scientific workflow toolkit (kepler-project.org) is utilized for implementing and automating BioEarth workflows.

BioEarth has a modular/flexible framework and is designed such that only some of the components may be utilized for the specific research question under investigation; e.g., for a question involving quantification of the impacts of water scarcity on irrigated agriculture without considering atmospheric feedbacks, the interactions between land surface processes, reservoir operations, and interruption of water rights can be simulated without tight coupling to atmospheric models. In determining which components to include, our goal is to match the level of model integration to the interconnectivity of the decision-process under investigation. The level of integration needed for informing specific management activities is partially determined through feedback from our stakeholders (see Section 4); e.g., agricultural producers are asked about the extent to which various environmental factors play a role in their decision-making. This approach minimizes model complexity and computational resources while still capturing key interactions. Furthermore, incorporating too much complexity (for a specific question) into an integrated model can have negative consequences. As an example, coupling a land surface model to an atmospheric model can result in large biases and reduced performance in informing management decisions, as compared to driving a land surface model with observed meteorology or with biascorrected atmospheric model output (Liu et al. 2013). This loss of accuracy may prohibit a coupled model's usefulness for specific management decisions. Regardless of the complexity of the model chosen for each application, when a coupled model is used 
for informing decision-making, rigorous testing is required to evaluate model results and enhance the usability of model outputs.

\subsection{Land-atmosphere coupling and atmospheric model integration}

We take advantage of the CESM flux coupler that facilitates coupling of earth system components to allow data exchange between, e.g., atmospheric and land surface models. This flux coupler is modular and allows for several options for each of the land and atmosphere components. For BioEarth, we include two additional land surface options (see Section 3.4): 1) VIC-CropSyst, and 2) Upscaled-RHESSys. The flux coupler provides flexibility for the atmospheric and land surface models to be applied on their own grids and spatial resolutions. This is particularly important for coupling WRF to Upscaled-RHESSys, which runs on variably-sized watershed units rather than grid-cell units. For coupling with an atmospheric model, VIC requires code restructuring to adopt a space-before-time structure so that state variables for all grid-cells are updated before advancing to the next time step, which has been accomplished in other projects (Leung et al. 2011), but requires updating for BioEarth developments. The BioEarth project utilizes this modified version of VIC but with modifications and updates at the University of Washington through the Regional Arctic System Model (RASM) project (Maslowski et al. 2012).

For applications involving atmospheric chemistry, the CMAQ model can either be run offline from or fully-coupled to WRF. The fully coupled version accounts for radiative feedbacks between chemistry and physics by considering ozone effects on long-wave radiation and aerosol effects on both short- and long-wave radiation (Wong et al. 2012). For BioEarth, the CESM framework will be adapted to pass hydrologic information to MEGAN to determine biogenic emissions needed by CMAQ.

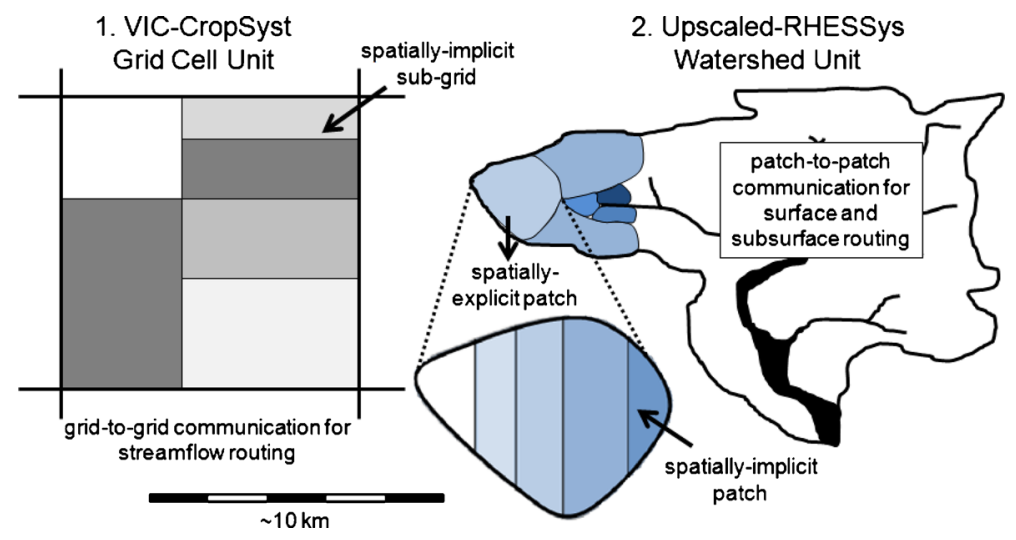

Fig. 3 Comparison of the Upscaled-RHESSys watershed unit to the VIC-CropSyst grid-cell unit. The UpscaledRHESSys approach is considered "bottom-up" because its native spatial resolution is relatively high; fineresolution spatial heterogeneities are more fully captured than VIC because the watershed units are comprised of relatively fine-resolution spatially-explicit patches, which are in turn comprised of spatially-implicit or "aspatial" patches. The sizes of the explicit and implicit patches within Upscaled-RHESSys are determined through model sensitivity experiments across biomes. Alternatively, the VIC-CropSyst approach is considered "top-down" because VIC was originally developed for global-scale applications at relatively coarse resolutions. VIC gridcells should not be implemented at resolutions typically implemented by RHESSys because lateral hydrologic connectivity does not exist between cells 


\subsection{Terrestrial model integration}

The modular nature of the BioEarth framework allows users to apply the land surface model most appropriate for each research question. Two unique land surface models are in development for BioEarth: 1) VIC-CropSyst primarily for applications involving intensely-managed cropping systems, and 2) Upscaled-RHESSys primarily for applications involving less intensely-managed forest and rangeland ecosystems, but with eventual capabilities to handle cropping systems. RHESSys also includes capabilities to simulate urban environments, allowing for investigation around questions that involve these landscapes, such as urban expansion.

VIC and RHESSys were originally developed for different scales and applications. VIC was developed as a land surface model that can be used with atmospheric models and includes detailed process-based parameterizations for water and energy fluxes with the flexibility to run at sub-daily time-steps, both of which are necessary for atmospheric coupling (Liang et al. 1994). Like all macro-scale land surface models, VIC is coarse in its representation of lateral hydrologic processes. To reduce computation time and avoid breaking model assumptions, grid-cells are necessarily large $\left(\sim 10^{7}-10^{10} \mathrm{~m}^{2}\right)$, and sub-grid heterogeneity (e.g., in land cover, elevation, saturated extent, and snow cover) is represented implicitly in space through empirical relationships (Fig. 3). Lateral fluxes are not specifically simulated within VIC while a postprocess is available for streamflow routing. Conversely, while RHESSys is less detailed than VIC in representing vertical fluxes, it is more detailed in space, capturing surface/subsurface lateral flow between neighboring patches $\left(\sim 10^{1}-10^{4} \mathrm{~m}^{2}\right)$. Below, we describe the development of the two BioEarth land surface models which are based on VIC and RHESSys, with elements of CropSyst. VIC-CropSyst's strength lies in capturing land-atmosphere interactions, particularly as related to agricultural activities; while Upscaled-RHESSys' strength lies in capturing hydro-ecological processes that are governed by relatively fine-scale spatial heterogeneities and lateral hydrologic connectivity, e.g., the role of soil moisture redistribution in impacting ecological hot-spots in terms of $\mathrm{C}: \mathrm{N}: \mathrm{H}_{2} \mathrm{O}$ dynamics.

\subsubsection{Development of VIC-CropSyst}

In the integrated VIC-CropSyst model, CropSyst is embedded into VIC as a sub-model simulating vegetation dynamics and biogeochemistry, providing the model's capacity to investigate interactions between hydrologic and agro-ecological systems. VIC retains simulations of hydrologic processes with the exception of transpiration. It is improved to simulate crop-specific potential evapotranspiration; irrigation technology-specific evaporative losses; vertical drainage of moisture through tightly-spaced soil moisture layers; and humidity following irrigation. CropSyst models transpiration, crop yield, nutrient leaching, and greenhouse gas emissions, which are provided as inputs to the economic, atmospheric, and aquatic models.

Because of its coarse spatial resolution, VIC-CropSyst does not resolve individual farms, as specific crop types are represented implicitly as sub-grid classes; i.e., within each grid-cell, a particular crop is assigned a percentage of the grid-cell area and its location and extent are treated as non-spatial elements (Fig. 3). Modeled variables are usually (but not necessarily) aggregated over the sub-grids to produce a grid-cell average prior to subsequent analysis. In terms of decision support, VIC-CropSyst's strength lies in producing information as to the broader implications of widespread changes in irrigation, fertilization, or crop management decisions; in addition to being a powerful tool for large-scale studies of land-atmosphere interactions. 


\subsubsection{Development of upscaled-RHESSys}

Upscaled-RHESSys includes several additional developments for inclusion in the BioEarth framework.

1) While RHESSys is well developed for forested landscapes, for BioEarth it is modified to better represent biogeochemical processes occurring in rangeland (currently) and cultivated cropping systems (eventually) through an integrated $\mathrm{C}$ allocation scheme taking into account both resource limitation and plant growth, dynamic $\mathrm{C}: \mathrm{N}$ ratios in leaves, inclusion of a $\mathrm{C}$ and $\mathrm{N}$ pool that represents the regenerative (or harvested) portion of the crop, biomass removal mechanisms related to harvesting and grazing, and other additional capabilities to simulate hydro-ecological responses to forest, rangeland, and cropping systems management.

2) To couple RHESSys as a land surface sub-model to WRF, it will be adapted to run at the same temporal scale as WRF, and its full energy budget will be refined to simulate subsurface thermodynamics, radiation transfer through the canopy, and energy balancedriven snow processes.

3) To reduce compute time, RHESSys is being adapted to allow for larger patch sizes by incorporating within-patch heterogeneity through non-spatial elements analogous to VIC sub-grids (i.e., "embedded aspatial patches"). Therefore, we combine aspatial approaches used in hydrologic models such as VIC with explicit hydrologic routing approaches used in models such as the Distributed Hydrology Soil-Vegetation Model (DHSVM; Wigmosta et al. 1994) (see Fig. 3 caption for details). We argue that this approach will be substantially more efficient but will still allow users to represent differences that arise due to lateral connectivity and spatial heterogeneity in watershed hydrology and ecosystem dynamics. Figure 3 illustrates the differences between Upscaled-RHESSys watershed units and the VIC-CropSyst grid-cell units.

\subsection{Aquatic model integration}

The water resources of the CRB are heavily managed and this human alteration of the hydrologic cycle needs to be considered to better estimate seasonal available water supply. We take a two-pronged approach involving 1) an offline reservoir model (ColSim) that has detailed information on reservoir operating rules and, 2) a generic store-and-release algorithm that can be fully-coupled with the hydrologic model. The generic algorithm will estimate storage and releases either based on time-series results from the offline reservoir model or on empirical calculations similar to Voisin et al. (2013) or Biemans et al. (2011). This two-pronged approach gives the flexibility of choosing the framework best suited to a specific question.

NEWS sub-models have been successfully applied at sub-basin spatial scales (e.g., Harrison et al. 2010) for various forms of $\mathrm{C}$ and nutrients. In BioEarth, NEWS is utilized and evaluated for sub-basins within the CRB to predict seasonal fluxes, sources, and sinks for various forms (inorganic/organic, particulate/dissolved) of $\mathrm{N}$ and $\mathrm{C}$. NEWS takes as input simulated hydrologic and $\mathrm{N}$ fluxes from the terrestrial models, meteorological information from WRF, and water storage from the reservoir models.

\subsection{Economic model integration}

The purpose of integrating economic models into mechanistic biophysical models is to base human action and their influences on biogeochemical cycles (e.g., from land use, nutrient 
loading, and irrigation) on microeconomic foundations rather than on arbitrary rules (Harou et al. 2009). A two-pronged approach will be taken to model economic behavior by utilizing 1) a CGE model of the regional economy and 2) an ABM. While both work from a foundation of economically-optimizing decision-makers, they differ significantly in terms of temporal/spatial disaggregation and model structure. The CGE and ABM models will be run separately but integrated on annual time-steps. Multiple groups have applied CGE modeling of regional economies to represent agricultural production (for a review, see Harou et al. 2009). CGE modeling is suited for capturing the complex array of possible economic responses to changing conditions, including input/output substitution and investment. Hydrologic models inform water availability, and crop growth models are used to parameterize crop production functions for varying levels of deficit irrigation under a range of atmospheric conditions. Input use determined by the CGE model defines the timing of water use and other inputs, including fertilizers that can be fed back into other models. Sub-regions are differentiated by their parameterization and constraints, which is usually important for representing production in irrigated agriculture where water is a limiting resource.

In many instances the lack of spatial resolution in CGE models becomes problematic. While the development of sub-regions within the regional CGE model can account for spatial heterogeneity in growing conditions and resource constraints, they usually involve a significant level of spatial aggregation and are ill-suited towards modeling spatially-dependent decisionmaking. This is an important limitation because of the extensive spatial interactions related to water movement that result from farm-level adaptation, water transfers, or any other changes in water management. This weakness provides the motivation for the development of an ABM.

ABM allows for improved modeling of nutrient use and water quality impacts by more precisely locating each agent in space relative to water systems; and it is possible to separate the region of study into grid-cells that match those of the biophysical models. This allows for full coupling between human and environmental models. Adoption of approaches like ABM among economists remains small relative to more accepted economic modeling frameworks because they typically require a more simplistic representation of economic decision-making. However, they are becoming more common as recognition of the importance of spatial interactions has grown (Irwin 2010).

\section{Stakeholder engagement process and communication research}

Scientists are now more than ever asked to consider not only the scientific credibility and adequacy of their work, but also its salience to the needs of the public and its legitimacy among stakeholders beyond their scientific peers (Cash et al. 2003). Creating more opportunities for interactions among scientists and potential users of climate information is one approach to producing scientific information that is also actionable. In response, EaSM research initiatives have begun to explicitly integrate novel approaches for stakeholder engagement into the modeling process. This is often conceptualized as merely communication of research results after a project is completed (Green et al. 2009). Increasingly, the value of engaging with stakeholders during the process of knowledge production is recognized, but such engagement is limited in practice (Callon 1999; Phillipson et al. 2012).

BioEarth's communications team provides multiple functions, including coordinating and implementing stakeholder engagement throughout the duration of the project by facilitating interactive communication between model developers and non-academic practitioners (Section 4.1). In addition, the team is conducting research focused on assessing expectations about stakeholder engagement among both modelers and stakeholders (Section 4.2). 


\subsection{Stakeholder engagement}

For stakeholders to be engaged in the model development process, opportunities for stakeholders to influence how research questions are prioritized must be created, and bi-directional communication between researchers and stakeholders must be facilitated. A series of stakeholder advisory workshops organized around specific resource management issues are occurring between the years of 2013 and 2016. Each workshop focuses on different management issues of critical concern to the region, including $\mathrm{N}$ and $\mathrm{C}$ management, water quantity/quality, forest and rangeland management, and air quality. Stakeholders participating in these workshops include a broad set of individuals who could benefit from using model results to inform their decision-making; these include representatives from industry, government agencies (federal, state, local and tribal), and environmental and other advocacy organizations. These workshops are designed to allow for in-depth discussion of stakeholders' issue-specific information needs and preferences for how model outputs, complexity, and uncertainty might be best communicated. The four goals of these stakeholder advisory meetings are to 1) elicit stakeholders' insights, perspectives and recommendations to inform prioritizations of model development; 2) communicate the potential value and utility of the model to stakeholders and provide them with an enhanced understanding of the model development process, complexity, and uncertainty of outputs; 3) establish positive, productive relationships and enhance mutual understanding between a broad range of stakeholders and the modeling team; and 4) increase researchers' understanding of the factors driving resource management decisions and the information needs of decision-makers to help the modeling team understand how stakeholders prioritize various environmental and economic concerns.

Based on the interactions, feedback and surveys during and after the first two stakeholder workshops that occurred in February 2013, an innovative system for analyzing and acting upon stakeholders' feedback was devised. The stakeholder input was categorized into discrete recommendations about model components, capabilities and scenarios that could be addressed, and these recommendations were arranged in a spreadsheet with details about frequency of recommendation, the number of individuals with expertise in that specific area, and the spatial and temporal scales at which each recommendation would need to be addressed. Once this database was created it was shared with all of the BioEarth modelers and scientists, and served as a focusing tool for a project-wide process of prioritizing the recommendations according to the BioEarth project scope and available resources.

\subsection{Communications research}

The communication team is also analyzing the perceptions and understandings of stakeholders and scientists throughout the research process using a temporal series of surveys and interviews, with a focus on 1) the scientists' perspectives on stakeholder engagement; and 2) the stakeholder's and scientists' perceptions of the utility and relevance of the integrated model.

As stakeholder engagement in environmental modeling is increasingly expected by funding agencies, understanding the range of perceptions on the value of stakeholder engagement can help facilitate productive interactions. Acknowledging this, the BioEarth communications research team began with analysis of the scientists' perspectives on stakeholder engagement as well as model utility during the first year of the project (Allen et al. 2013). Results demonstrate a broad range of perceptions about the value of the stakeholder engagement process and varying expectations for the production of decision-relevant information within BioEarth. Researchers who anticipate the model to be relevant to policy decision-making rank communication with stakeholders as a central challenge in the project, while those researchers 
who are thinking about the model as something primarily relevant to academic audiences tend to focus on technical challenges associated with model integration rather than the model's practical or social relevance. The communications team is continuing to conduct surveys and interviews with researchers and stakeholders to understand their perspectives on model utility and the stakeholder engagement process.

\section{The way forward for BioEarth}

A primary goal of the BioEarth project is to move an integrated modeling project along the continuum from generating primarily scientific knowledge to also producing actionable information that can inform decision-making. Because of its high degree of integration, BioEarth's strength is in providing a fuller context of land use decision-making at the regional scale. The BioEarth framework can highlight environmental and economic trade-offs among various management scenarios to inform a variety of decision-makers with different priorities, concerns, and constraints.

BioEarth has several unique aspects that enable movement along this continuum, e.g. through our engagement of non-academic stakeholders to inform model development, scenarios, and output. The social and technical learning anticipated from this project involves broad potential for contributing and reinforcing the nascent paradigm shift in expectations for environmental modeling with regard to relevance and utility of the modeling process. Lessons learned from researchers and stakeholders involved in BioEarth could be useful for other environmental modeling projects, in much the same way that BioEarth has learned from more mature EaSM activities such as PRIMA (Kraucunas et al. 2013). BioEarth is most similar to PRIMA, particularly because both projects aim to inform resource management decisions. While sharing this objective, the same land/atmosphere coupling infrastructure, and some model components (e.g., WRF), there are important distinctions. PRIMA emphasizes the energy system (from large-scale energy economics to fine-scale models of building energy use, electricity operation, and siting of energy infrastructure) and its interactions with air, land, and water resources; while BioEarth emphasizes agriculture (cropland, rangeland, and forests) and its interactions with air, land, and water resources. Because of this, biogeochemistry and dynamic vegetation (and their response to changes in climate and management activities) are primary foci of investigation for BioEarth, while biogeochemistry has yet to be implemented in PRIMA. For this, BioEarth applies a bottom-up approach for simulating coupled C: $\mathrm{N}: \mathrm{H}_{2} \mathrm{O}$ interactions, with the upscaling strategy being developed across a gradient of biomes, a unique approach among regional EaSMs. Finally, there is an urgent need for the development of multiple regional EaSMs because a diversity of approaches allows for a better understanding of overall uncertainty in predicting decadal-scale climate/land/water/human interactions due to model structure.

The BioEarth project is currently halfway through its initial five-year funding period, by the end of which our goal is to have a rigorously-tested framework that includes the primary linkages between model components; a foundation that we can continue to build on over time. Some achievements to date include development of a detailed land cover dataset to be used for all component models; design of a tool for building and automating modular workflows; development, implementation, and testing of WRF-VIC; implementation and operationalization of CMAQ; completion, testing and application of the VICCropSyst integrated model; refinement, development, and initial upscaling of RHESSys over forested and grassland ecosystems; application of the NEWS dissolved inorganic nitrogen model by driving it with output from BioEarth's terrestrial models; initial 
implementation of the CGE model using crop response curves generated by VICCropSyst; completion of the initial survey of scientists' perceptions on stakeholder engagement; and completion of the first set of stakeholder workshops, with outputs that are informing further model development (e.g., a prioritization of processes to include) and scenarios (e.g., adaptation strategies that producers are considering and seeking information with regards to potential consequences). Multiple model integration challenges remain to be implemented and/or tested, including aggregation/disaggregation of variables when running coupled models at different spatial and temporal resolutions, version control (i.e., some components models, such as VIC, were significantly modified for the coupled framework and are therefore not routinely updated to the most advanced version of the model; others, such as RHESSys, incorporate BioEarth-specific advancements directly into the working version), and characterization/handling of uncertainty and biases when running tightly-integrated simulations such that modeled information is usable for resource management decisions. Currently, enough of this modular framework has been built that we have begun implementing specific applications and running scenarios, the outputs of which are being provided to our stakeholder advisory group for feedback.

Our intent is that the BioEarth project will continue to evolve over the long term, increasing its generation of both scientific knowledge and actionable information. We continue to extend our collaboration network and seek additional funds to incorporate missing processes (such as deep groundwater dynamics, fire behavior, or biotic disturbance) and to apply and rigorously test the model for specific applications. As BioEarth is composed primarily of mechanistic models, it can be readily applied in other regions and will be a powerful tool for exploring the water-food-climate nexus. The BioEarth framework is flexible in that it can accommodate highly detailed information only available in specific regions (such as water rights, instream flow rules, and reservoir operations) or it can use simplified rules where this information is not available, lending itself well to application in developing countries. Finally, the stakeholder advisory process is evolving. The multiplicity of decisions that are relevant to the model scope complicate this process, and we are continuing to develop ways to learn from our stakeholder advisors to improve both the model and our communication about the model output, complexity, and uncertainty.

Acknowledgments This research is funded from the Department of Agriculture, National Institute of Food and Agriculture grant number 2011-67003-30346. Funding for Dr. Nijssen's contribution to this project is from the Regional Arctic Systems Model (RASM) through Department of Energy grant number DE-SC0006856. The authors would like to thank our peer reviewers and our stakeholders who have contributed invaluable insights to the BioEarth Project. Finally, we thank three anonymous reviewers whose comments helped to improve this manuscript.

Open Access This article is distributed under the terms of the Creative Commons Attribution License which permits any use, distribution, and reproduction in any medium, provided the original author(s) and the source are credited.

\section{References}

Allen E, Kruger C, Leung F-Y, Stephens JC (2013) Diverse perceptions of stakeholder engagement within an environmental modeling research team. J Environ Stud Sci 3:343-356 
Biemans H, Haddeland I, Kabat P, Ludwig F, Hutjes RWA, Heinke J, von Bloh W, Gerten D (2011) Impact of reservoirs on river discharge and irrigation water supply during the 20th century. Water Resour Res 47, W03509. doi:10.1029/2009WR008929

Byun D, Schere KL (2006) Review of the governing equations, computational algorithms, and other components of the models-3 Community Multiscale Air Quality (CMAQ) modeling system. Appl Mech Rev 59:51-77

Callon M (1999) The role of lay people in the production and dissemination of scientific knowledge. Sci Technol Soc 4:81-94

Cash DW, Clark WC, Alcock F, Dickson NM, Eckley N, Guston DH, Jäger J, Mitchell RB (2003) Knowledge systems for sustainable development. Proc Natl Acad Sci 100:8086-8091

Drewniak B, Song J, Prell J, Kotamarthi VR, Jacob R (2013) Modeling agriculture in the community land model. Geosci Model Dev 6:495-515

Gent PR, Danabasoglu G, Donner LJ, Holland MM, Hunke EC, Jayne SR, Lawrence DM, Neale RB, Rasch PJ, Vertenstein M, Worley PH, Yang Z-L, Zhang M (2011) The community climate system model version 4. J Clim 24:4973-4991

Giorgi F (1995) Perspectives for regional earth system modeling. Glob Planet Change 10:23-42

Green LW, Glasgow RE, Atkins D, Stange K (2009) Making evidence from research more relevant, useful, and actionable in policy, program planning, and practice: slips “Twixt Cup and Lip". Am J Prev Med 37:S187S191

Guenther AB, Jiang X, Heald CL, Sakulyanontvittaya T, Duhl T, Emmons LK, Wang X (2012) The model of emissions of gases and aerosols from nature version 2.1 (MEGAN2.1): an extended and updated framework for modeling biogenic emissions. Geosci Model Dev 5:1471-1492

Hamlet AF, Lettenmaier DP (1999) Effects of climate change on hydrology and water resources in the Columbia River Basin1. JAWRA J Am Water Resour Assoc 35:1597-1623

Harou JJ, Pulido-Velazquez M, Rosenberg DE, Medellín-Azuara J, Lund JR, Howitt RE (2009) Hydro-economic models: Concepts, design, applications, and future prospects. J Hydrol 375:627-643

Harrison JA, Bouwman AF, Mayorga E, Seitzinger S (2010) Magnitudes and sources of dissolved inorganic phosphorus inputs to surface fresh waters and the coastal zone: A new global model. Glob Biogeochem Cycles 24, GB1003. doi:10.1029/2009GB003590

Hibbard KA, Janetos AC (2013) The regional nature of global challenges: a need and strategy for integrated regional modeling. Climatic Change 116(3-4), doi: 10.1007/s10584-012-0674-3

Irwin EG (2010) New directions for urban economic models of land use change: incorporating spatial dynamics and heterogeneity. J Reg Sci 50:65-91

Jaffe D, Anderson T, Covert D, Kotchenruther R, Trost B, Danielson J, Simpson W, Berntsen T, Karlsdottir S, Blake D, Harris J, Carmichael G, Uno I (1999) Transport of Asian air pollution to North America. Geophys Res Lett 26:711-714

Katz RW, Brown BG (1992) Extreme events in a changing climate: Variability is more important than averages. Clim Change 21:289-302

Kitzberger T, Brown PM, Heyerdahl EK, Swetnam TW, Veblen TT (2007) Contingent Pacific-Atlantic Ocean influence on multicentury wildfire synchrony over western North America. Proc Natl Acad Sci 104:543-548

Kraucunas, IP, Clarke LE, Dirks JA, Hathaway J, Hejazi MI, Hibbard KA, Huang M, Jin C, Kintner-Meyer MCW, van Dam KK, Leung LR, Li H-Y, Moss RH, Peterson MJ, Rice JS, Scott MJ, Thomson AM, Voisin N, West TO (2013) Investigating the Nexus of climate, energy, water, and land at decision-relevant scales: the Platform for Regional Integrated Modeling and Analysis (PRIMA). Climatic Change, accepted

Lamarque J-F, Emmons LK, Hess PG, Kinnison DE, Tilmes S, Vitt F, Heald CL, Holland EA, Lauritzen PH, Neu J, Orlando JJ, Rasch PJ, Tyndall GK (2012) CAM-chem: description and evaluation of interactive atmospheric chemistry in the Community Earth System Model. Geosci Model Dev 5:369-411

Lawrence DM, Oleson KW, Flanner MG, Thornton PE, Swenson SC, Lawrence PJ, Zeng X, Yang Z-L, Levis S, Sakaguchi K, Bonan GB, Slater AG (2011) Parameterization improvements and functional and structural advances in Version 4 of the Community Land Model. J Adv Model Earth Syst 3

Lemos MC, Kirchhoff CJ, Ramprasad V (2012) Narrowing the climate information usability gap. Nat Clim Change 2:789-794

Leung LR, Huang M, Qian Y, Liang X (2011) Climate-soil--vegetation control on groundwater table dynamics and its feedbacks in a climate model. Clim Dyn 36:57-81

Liang X, Lettenmaier DP, Wood EF, Burges SJ (1994) A simple hydrologically based model of land surface water and energy fluxes for general circulation models. J Geophys Res Atmospheres 99:14415-14428

Liu J, Dietz T, Carpenter SR, Alberti M, Folke C, Moran E, Pell AN, Deadman P, Kratz T, Lubchenco J, Ostrom E, Ouyang Z, Provencher W, Redman CL, Schneider SH, Taylor WW (2007) Complexity of coupled human and natural systems. Science 317:1513-1516

Liu M, Rajagopalan K, Chung SH, Jiang X, Harrison J, Nergui T, Guenther A, Miller C, Reyes J, Tague C, Choate J, Salathé EP, Stöckle CO, Adam JC (2013) What is the importance of climate model bias when 
projecting the impacts of climate change on land surface processes? Biogeosci Discuss 10(11):1714517192. doi:10.5194/bgd-10-17145-2013

Maslowski W, Clement Kinney J, Higgins M, Roberts A (2012) The future of Arctic Sea Ice. Annu Rev Earth Planet Sci 40:625-654

Mote PW, Parson EA, Hamlet AF, Keeton WS, Lettenmaier D, Mantua N, Miles EL, Peterson DW, Peterson DL, Slaughter R, Snover AK (2003) Preparing for climatic change: the water, salmon, and forests of the Pacific Northwest. Clim Change 61:45-88

Ozdogan M, Gutman G (2008) A new methodology to map irrigated areas using multi-temporal MODIS and ancillary data: an application example in the continental US. Remote Sens Environ 112(9):3520-3537

Phillipson J, Lowe P, Proctor A, Ruto E (2012) Stakeholder engagement and knowledge exchange in environmental research. J Environ Manag 95:56-65

Reid WV, Chen D, Goldfarb L, Hackmann H, Lee YT, Mokhele K, Ostrom E, Raivio K, Rockström J, Schellnhuber HJ, Whyte A (2010) Earth system science for global sustainability: grand challenges. Science 330:916-917

Rowan TSC, Maier HR, Connor J, Dandy GC (2011) An integrated dynamic modeling framework for investigating the impact of climate change and variability on irrigated agriculture. Water Resour Res 47 , W07520. doi:10.1029/2010WR010195

Seitzinger, SP, Harrison JA, Dumont E, Beusen AHW, Bouwman AF (2005). Sources and delivery of carbon, nitrogen, and phosphorus to the coastal zone: an overview of Global Nutrient Export from Watersheds (NEWS) models and their application. Global Biogeochem Cy 19(4). doi:10.1029/2005GB002606

Skamarock WC, Klemp J, Dudhia J, Gill DO, Barker DM, Duda MG, Huang X-Y, Wang W, Powers, J (2008) A description of the advanced research WRF version 3. .NCAR Tech. Note TN- 475_STR, 113pp

Smith MS, Horrocks L, Harvey A, Hamilton C (2011) Rethinking adaptation for a $4^{\circ} \mathrm{C}$ world. Philos Trans R Soc Math Phys Eng Sci 369:196-216

Stöckle CO, Donatelli M, Nelson R (2003) CropSyst, a cropping systems simulation model. Eur J Agron 18: 289-307

Tague CL, Band LE (2004) RHESSys: Regional Hydro-Ecologic Simulation System-An object-oriented approach to spatially distributed modeling of carbon, water, and nutrient cycling. Earth Interact 8:1-42

Voisin N, Li H, Ward D, Huang M, Wigmosta M, Leung LR (2013) On an improved sub-regional water resources management representation for integration into earth system models. Hydrol Earth Syst Sci Discuss 10:3501-3540

Wang S-Y, Gillies RR, Jin J, Hipps LE (2009) Recent rainfall cycle in the Intermountain Region as a quadrature amplitude modulation from the Pacific decadal oscillation. Geophys Res Lett 36, L02705. doi:10.1029/ 2008GL036329

Washington WM, Buja L, Craig A (2009) The computational future for climate and Earth system models: on the path to petaflop and beyond. Philos Trans R Soc Math Phys Eng Sci 367:833-846

Weaver CP, Lempert RJ, Brown C, Hall JA, Revell D, Sarewitz D (2013) Improving the contribution of climate model information to decision making: the value and demands of robust decision frameworks. Wiley Interdiscip Rev Clim Change 4:39-60

Wharton S, Chasmer L, Falk M, Paw U KT (2009) Strong links between teleconnections and ecosystem exchange found at a Pacific Northwest old-growth forest from flux tower and MODIS EVI data. Glob Change Biol 15:2187-2205

Wigmosta MS, Vail LW, Lettenmaier DP (1994) A distributed hydrology-vegetation model for complex terrain. Water Resour Res 30:1665-1679

Wong DC, Pleim J, Mathur R, Binkowski F, Otte T, Gilliam R, Pouliot G, Xiu A, Young JO, Kang D (2012) WRF-CMAQ two-way coupled system with aerosol feedback: software development and preliminary results. Geosci Model Dev 5:299-312 